\title{
Occurrence of potential pathogenic Aeromonas species in tropical seafood, aquafarms and mangroves off Cochin coast in South India
}

\author{
Alphonsa Vijaya Joseph, Raghul Subin Sasidharan, Harisree P. Nair and Sarita G. Bhat \\ Department of Biotechnology, \\ Cochin University of Science and Technology, Cochin, India \\ Corresponding author: Sarita G. Bhat, email: saritagbhat@gmail.com \\ Received: 02-11-2012, Accepted: 01-12-2012, Published online: 05-03-2013
}

\begin{abstract}
How to cite this article: Joseph AV, Sasidharan RS, Nair HP and Bhat SG (2013) Occurrence of potential pathogenic Aeromonas species in tropical seafood, aquafarms and mangroves off Cochin coast in South India, Vet. World 6(6): 300-306, doi: 10.5455/vetworld.2013.300-306
\end{abstract}

\begin{abstract}
Background: The genus Aeromonas include gram-negative, motile, facultative anaerobic, rod shaped and oxidase positive bacteria comprising several species, associated with the aquatic environment. Aeromonas species have been implicated in human pathogenesis and are linked with gastroenteritis, muscle infections, septicemia, and skin diseases. In fish they are renowned as enteric pathogens causing haemorrhagic septicemia, fin rot, soft tissue rot and furunculosis resulting in major die-offs and fish kills.
\end{abstract}

Aim: This study reports the occurrence of potential pathogenic Aeromonas sp. in tropical seafood (Squids, Prawns and Mussels), aquafarms and mangroves of Cochin, Kerala, South India.

Materials and Methods :Tropical seafood (Squid, Prawn and Mussel), sediment and water samples from aquafarms and associated mangroves were screened for Aeromonas contamination. The isolates were identified by $16 \mathrm{~S}$ rDNA sequence analysis and subjected to morphological and biochemical characterization. Haemolytic assay was used for determining pathogenicity of the organisms. Antibiotic susceptibility against 12 antibiotics were performed and the MAR index was calculated.

Results: A total of 134 isolates were recovered from the samples of which 15 were identified as Aeromonas species by $16 \mathrm{~S}$ rDNA sequence analysis and were assigned to 5 species namely, A. hydrophila, A. enteropelogenes, A. caviae, A. punctataand A. aquarorium. Morphological, biochemical and phylogenetic analyses revealed relatedness and variability among the strains. All the isolates were haemolytic on blood agar indicating their pathogenicity. The isolates exhibited varying degrees of resistance to vancomycin (86.66\%), ampicillin (46.66\%), nalidixic acid (20\%), tetracycline (6.66\%), co-trimaxozole (6.66\%) and rifampicin $(6.66 \%)$ and were susceptible to antibiotics like gentamycin, streptomycin, trimethoprim, azithromycin, cefixime and chloramphenicol. $20 \%$ of Aeromonas sp. showed MAR index $\geq 0.2$ indicative of the high risk environment.

Conclusion: The presence of Aeromonas sp. has been recognised as a potential health risk and surveillance of this pathogen is crucial for successful disease management and control.

Keywords: 16S rDNA analysis, Aeromonas sp., antibiotic susceptibility tests, aquafarm, mangrove, pathogenic, phylogenetic tree, seafood

\section{Introduction}

Human demand for seafood has nudged the aquaculture industry to establish as a major source of excellent quality proteins and healthy oils by intensive and semi-intensive culture methods, with production reaching almost $50 \%$ of the total fish production including marine and freshwater species for human consumption [1]. Aquaculture farms, associated mangroves and seafood are prospective reservoirs of pathogenic bacteria and these realms play significant roles in ecological and epidemiological studies. Seafood harbours pathogenic microorganisms due to the texture of their flesh and also their microbe laden habitat. Contaminated seafood and their products therefore pose health risks to consumers.

This article is an open access article licensed under the terms of the Creative Commons Attribution License (http://creativecommons. org/licenses/by/2.0) which permits unrestricted use, distribution and reproduction in any medium, provided the work is properly cited.
Genus Aeromonas comprise non-motile psychrophilic and motile mesophilic Gram negative bacteria and include 15 species, being distributed ubiquitously in aquatic environments and are of increasing importance as seafood and waterborne pathogens [2]. Seven species causing gastroenteritis in adults [3] and in children [4], cellulitis [5] and septicaemia [6] are cause for human concern. They have also been implicated in peritonitis, meningitis and eye infections on rare occassions [7]. In addition, Aeromonas species are also etiological agents of fish diseases like furunculosis [8], septicaemia [9] and skinulcers [10].

A. hydrophila, and A.caviae are considered major pathogens most commonly implicated in human intestinal infections [11] and also account for more than $95 \%$ of all blood-borne infections [12]. Pathogenicity by A. enteropelogenes is attributed to the production of enterotoxins in humans and in fishes [13]. A. aquariorum was the first species to be isolated 
from ornamental fishes and is associated with diarrhoea, bacteremia, wound infections and other extra-intestinal infections [10].

Mesophilic species, namely A. hydrophila and A. veronii, cause an assortment of diseases in fish, including motile Aeromonas septicemia (MAS), fish rot, soft tissue rot and furunculosis resulting in major die-offs and fish kills around the globe [5]. Epizootic ulcerative syndrome (EUS) in fishes due to A. sobria caused great damage to fish farms in Bangladesh and India [14]. Most Aeromonas species are psychrotrophic and can grow at refrigerator temperatures, replicating at high salt concentrations [2] and preservation techniques seem ineffective in inhibiting the replication of these strains, which can multiply in packed food products and those under refrigeration. Aeromonas infections are probably the most common bacterial diseases to infect tropical fishes and prawns, with disease outbreaks being increasingly recognized as a significant constraint on aquaculture production, export and trade, consequently affecting the economic development of the sector in many countries.

Recognition and monitoring of the potential reservoirs of pathogenic bacteria and their drug resistance profile are essential in epidemiological and environmental studies to prevent possible health risks. The present study elaborates the increasing concern on the occurrence of prospective pathogenic species of Aeromonas in seafood, aquaculture farms and associated mangroves and the antibiotic resistance in these isolates.

\section{Materials and Methods}

Sampling and processing: Squid, prawn and mussel samples from the local fish market, water and sediment samples from aquaculture farms and their associated mangroves along the coastal area of Cochin were collected. All samples were collected in sterile polythene bags and processed within 2 hours of collection. $10 \mathrm{gm}$ each of seafood and sediment sample were aseptically inoculated into $90 \mathrm{ml}$ of alkaline peptone water for enrichment, after which $1 \mathrm{ml}$ of enriched culture was plated on Nutrient Broth agar (HiMedia Laboratories, India) plates by the pour plate method at regular intervals of 4 hours. The plates were incubated at $37^{\circ} \mathrm{C}$ for $18-24$ hours and isolated colonies were picked, purified and stored.

Identification of Aeromonas sp.: Genomic DNA was isolated [15]. Briefly cells from a 24 hour LB culture were harvested by centrifugation (6000 r.p.m. for 10 min), resuspended in TE buffer $(10 \mathrm{mM}$ Tris/ $\mathrm{HCl}, 1$ mM EDTA, pH 8.0), treated with $10 \%$ (w/v) SDS and proteinase $\mathrm{K}(20 \mathrm{mg} / \mathrm{ml})($ Sigma $)$ and incubated at $37{ }^{\circ} \mathrm{C}$ for 1 hour. After incubation, $10 \%$ cetyl trimethyl ammonium bromide (CTAB) in $0.5 \mathrm{M} \mathrm{NaCl}$ was added and the mixture incubated at $65^{\circ} \mathrm{C}$ for $10 \mathrm{~min}$. The aqueous phase was treated with double volume of phenol: chloroform: isoamyl alcohol (25:24:1) and the DNA pellet was washed with absolute ethanol and suspended in TE. The concentration was estimated spectrophotometrically and appropriate dilutions (50$100 \mathrm{ng}$ ) were used as template for PCR reactions.

$16 S$ rDNA sequence analysis: Identification of the Aeromonas strains was done by analysis of partial $16 \mathrm{~S}$ rDNA sequences. A portion of the $16 \mathrm{~S}$ rRNA gene (1.5kb) was amplified from the genomic DNA [16-19] using a set of primers (F 5' AGTTTGATCCTGGCTCA 3' and R 5' ACGGCTACCTTGTTACGACTT3') targeting the 16S rRNA gene. Products after PCR amplification were purified by gene clean kit (Bangalore Genei). The products were sequenced by Sanger's Dideoxy method using ABI 3730 Excel and the identity of the sequences was determined using BLAST [20].

The phylogenetic tree was constructed using the Neighbor-Joining method [21]. The evolutionary distances were computed using the Tajima-Nei method [22] and evolutionary analyses were conducted in MEGA5: Molecular Evolutionary Genetics Analysis (MEGA) software version 5.0 [23]. Statistical support for branching was estimated using 1000 bootstrap steps.

Morphological and biochemical characterization :All strains were tested for phenotypic traits like Gram staining, oxidase test, catalase test, Voges Proskauer's test, arginine utilisation, $3 \%$ salt tolerance test, ONPG, citrate utilisation, ornithine utilisation, and utilisation of carbohydrates like mannitol, arabinose, sucrose, glucose, salicin and cellobiose [24]. Hemolytic screening on sheep blood agar plates was used to test the pathogenicity of the isolates [25]. Isolates were also checked for growth on thiosulphate-citrate-bile-salt sucrose (TCBS) (HiMedia Laboratories, India) agar plates.

Antibiotic susceptibility tests: Pure cultures of the isolates were grown in Luria Bertani broth and resistance profiles were determined by the KirbyBauer disc diffusion method [26]. A single colony of the test strain was transferred into $3 \mathrm{ml}$ normal saline and turbidity adjusted to $0.5 \mathrm{McF}$ arland's standard. The bacterial suspension was swab inoculated onto Mueller- Hinton agar (HiMedia Laboratories, India) plates. Antibiotic discs (HiMedia Laboratories, India) used were Gentamycin $(10 \mu \mathrm{g})$, Streptomycin $(10 \mu \mathrm{g})$, Ampicillin $(10 \mu \mathrm{g})$, Nalidixic acid $(30 \mu \mathrm{g})$, Vancomycin $(30 \mu \mathrm{g})$ Co-trimoxazole $(23.75 \mu \mathrm{g})$, Trimethoprim $(5 \mu \mathrm{g})$, Cefixime $(5 \mu \mathrm{g})$, Azithromycin $(15 \mu \mathrm{g})$, Rifampicin $(5 \mu \mathrm{g})$, Tetracycline $(30 \mu \mathrm{g})$ and Chloramphenicol $(30 \mu \mathrm{g})$. The plates were incubated at $37^{\circ} \mathrm{C}$ for 24 hours and the result was interpreted as resistant, intermediate or sensitive based on the size of the inhibition zone as provided by the manufacturer. The Multiple Antibiotic Resistance (MAR) Index of an isolate was calculated using the formula $a / b$, where ' $a$ ' is the number of antibiotics to which the isolate was resistant and ' $b$ ', the number of antibiotics to which the isolate was exposed [27]. 

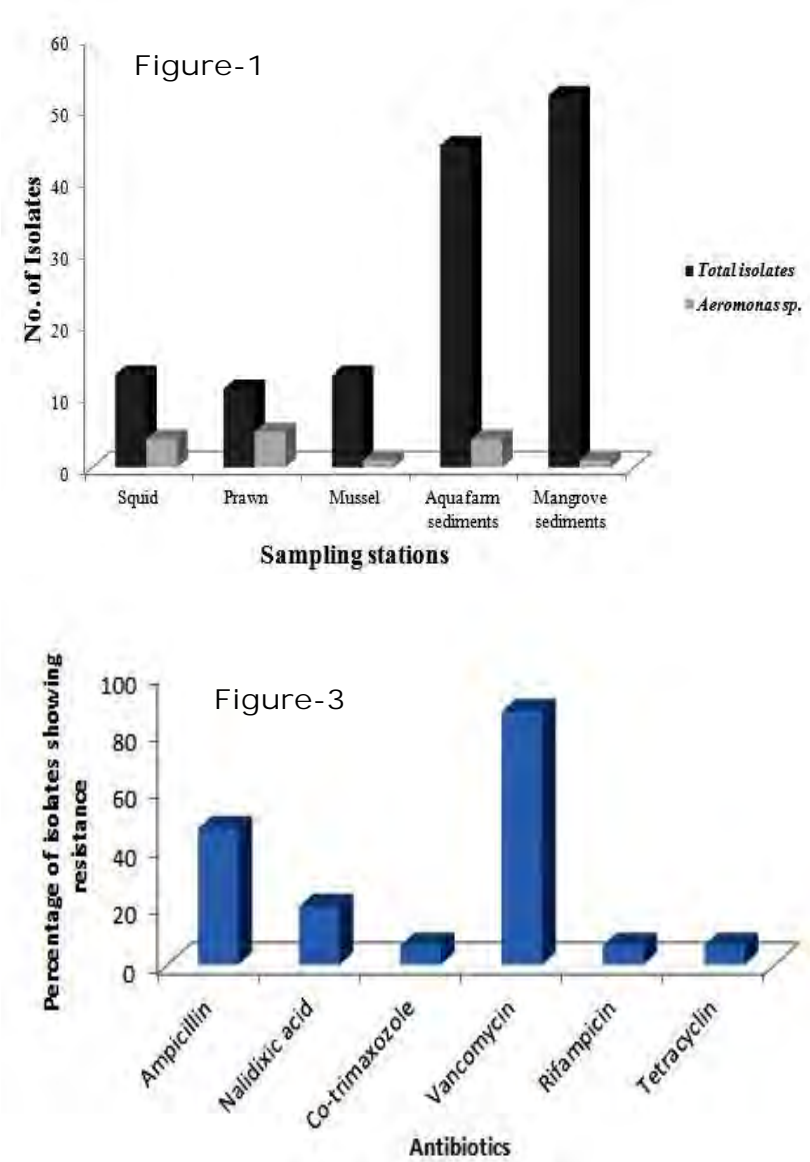

Results

I dentification of Aeromonas sp.: The total number of isolates obtained from the various samples was 134 . 16S rDNA sequencing identified 15 (11.2\%) of the 134 isolates, as Aeromonas sp. Their identity was confirmed by comparing the sequences with GenBank entries by BLAST [20] and the sequences were deposited in the GenBank and accession numbers obtained. The 15 isolates of Aeromonas sp. were assigned to five species, viz., A.punctata, A.caviae, A.enteropelogenes, A.hydrophila and A.aquarorium.

The distribution of the Aeromonas species in the studied samples is given in Figure 1. The highest incidence of Aeromonas strains was in prawns followed by squid and aquafarm sediments. Only one strain each from mussel and mangrove sediment were confirmed as Aeromonas sp. A. punctata and A. caviae were identified from squid, $A$. enteropelogenes and $A$. hydrophila from prawn, $A$. caviae from mussel, $A$. hydrophila from mangroves and $A$. hydrophila and $A$. aquarorium from aquafarms. Among the isolates, $A$. hydrophila was the predominant species followed by A. enteropelogenes.

16S rDNA sequence analysis: Phylogenetic relationship based on partial 16S rDNA sequences of the 15 isolates of Aeromonas is represented in Fig. 2. All the strains claded together separated from its outgroup in the phylogram. Within the major clades, alignment was such that the sequences of the same species aligned together, exhibiting the relatedness

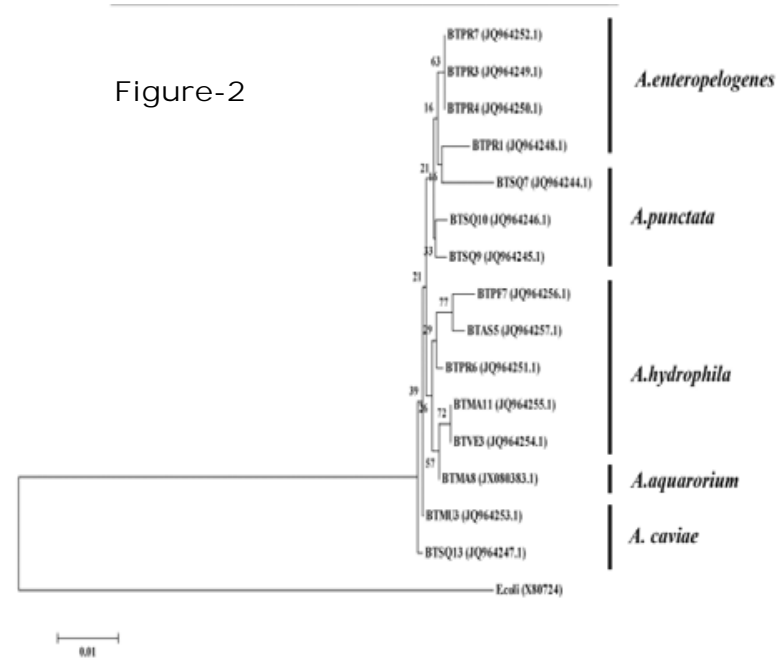

Figure-1. The distribution of the Aeromonas species from different sampling stations

Figure-2. Phylogenetic relationship based on partial 16S rDNA sequences of Aeromonas strains isolated from tropical seafoods, aquafarms and associated mangroves. The percentage of replicate trees in which the associated taxa clustered together in the bootstrap test (1000 replicates) is shown next to the branches. The analysis involved 15 nucleotide sequences and E.coli (accession number $\mathrm{X} 80724)$ as an outgroup. Accession numbers are given in parentheses.

Figure-3. Percentage of isolates showing resistance to tested antibiotics

between these strains. The strains BTPR7, BTPR3 and BTPR4 representing A.enteropelogenes grouped to form a clade. Two strains of $A$. punctata from squid, BTSQ9 and BTSQ10 grouped together whereas BTSQ7 aligned separately with $A$. enteropelogenes strain BTPR1 from prawn. The A. hydrophila strains formed a distinct clade despite the observed sequence diversity at the strain level. A.aquarorium strain BTMA8 clustered separately from the rest of the isolates and is placed nearer to A. hydrophila strains BTVE3 and BTMA11. The two strains of $A$. caviae, BTMU3 and BTSQ13, aligned together to form a distinct group.

Morphological and Biochemical Characterization: The biochemical characteristics of the 15 aeromonads are given in Table-1. All the isolates were Gram negative, catalase and oxidase positive, Voges-Proskauer negative, able to tolerate $3 \% \mathrm{NaCl}$ in the medium, ONPG positive, ornithine negative and fermented sucrose and glucose irrespective of the species. They exhibited variations with regard to the other properties tested like utilisation of arginine and citrate and carbohydrates like mannitol, salicin and cellobiose. With regard to the utilisation of arginine by the isolates, variations were observed between strains of the same species. All strains of $A$. enteropelogenes were able to utilise arginine except strain BTPR7 from prawn. Both strains of $A$. caviae, three strains of $A$. hydrophila and two strains of $A$. punctata tested negative for arginine utilisation whereas A. aquarorium was positive. Five 
Table-1. Phenotypic characteristics of Aeromonas sp. from seafoods, aquafarms and associated mangroves.

\begin{tabular}{|c|c|c|c|c|c|c|c|c|c|c|c|c|c|c|c|c|c|}
\hline Strains & TCBS & GS & C & 0 & VP & Arginine & $\mathrm{NaCl} 3 \%$ & ONPG & Citrate & Ornithine & Mannitol & Arabinose & Sucrose & Glucose & Salicin & Cellobiose & Hemolysis \\
\hline \multicolumn{18}{|c|}{ A.enteropelogenes } \\
\hline BTPR1 & G & - & + & + & - & + & + & + & + & - & + & - & + & + & + & + & $\beta$ \\
\hline BTPR3 & G & - & + & + & - & + & + & + & + & - & + & - & + & + & + & + & $\beta$ \\
\hline BTPR4 & Y & - & + & + & - & + & + & + & + & - & + & - & + & + & - & + & $\beta$ \\
\hline \multicolumn{18}{|l|}{ A. caviae } \\
\hline BTSQ13 & $\mathrm{Y}$ & - & + & + & - & - & + & + & + & - & + & + & + & + & + & + & $\alpha$ \\
\hline \multirow{2}{*}{\multicolumn{18}{|c|}{ A. hydrophila }} \\
\hline & & & & & & & & & & & & & & & & & \\
\hline BTPR6 & G & - & + & + & - & + & + & + & + & - & - & - & + & + & - & + & $\beta$ \\
\hline BTAS5 & Y & - & + & + & - & - & + & + & + & - & + & - & + & + & - & + & $\beta$ \\
\hline BTVE3 & Y & - & + & + & - & - & + & + & + & - & + & - & + & + & - & + & $\beta$ \\
\hline BTMA11 & Y & - & + & + & - & - & + & + & + & - & + & - & + & + & - & + & $\beta$ \\
\hline BTPF7 & $\mathrm{Y}$ & - & + & + & - & + & + & + & - & - & + & - & + & + & + & - & $\beta$ \\
\hline \multicolumn{18}{|c|}{ A. aquarorium } \\
\hline BTMA8 & $\mathrm{Y}$ & - & + & + & - & + & + & + & - & - & - & - & + & + & - & - & $\beta$ \\
\hline BTSQ7 & Y & - & + & + & - & - & + & + & + & - & + & - & + & + & - & + & $\alpha$ \\
\hline BTSQ9 & G & - & + & + & - & + & + & + & + & - & + & - & + & + & - & + & $\alpha$ \\
\hline BTSQ10 & $\mathrm{Y}$ & - & + & + & - & - & + & + & + & - & + & - & + & + & - & + & $\alpha$ \\
\hline
\end{tabular}

TCBS-Thiosulphate Citrate Bile Salt Agar; G- Green; Y- Yellow; GS- Gram staining; C-Catalase; O-Oxidase; + = Positive; - = negative

Table-2. Antibiotic profile of Aeromonas sp. from seafoods, aquafarms and associated mangroves.

\begin{tabular}{|c|c|c|c|c|c|c|c|c|c|c|c|c|c|}
\hline Isolate code & Species identified & G & $\mathbf{S}$ & A & $\mathbf{N}$ & $\mathbf{v}$ & Co & $\mathbf{T}$ & Cef & Azi & $\mathbf{R}$ & Tetra & Chlora \\
\hline $\begin{array}{l}\text { BTSQ } 7 \\
\text { BTSQ9 } \\
\text { BTSQ } 10 \\
\text { BTSQ } 13 \\
\text { BTPR } 1 \\
\text { BTPR } 3 \\
\text { BTPR } 4 \\
\text { BTPR } 6 \\
\text { BTPR } 7 \\
\text { BTMU } 3 \\
\text { BTVE } 3 \\
\text { BTMA } 8 \\
\text { BTMA } 11 \\
\text { BTPF } 7 \\
\text { BTAS } 5\end{array}$ & $\begin{array}{l}\text { A.punctata } \\
\text { A.punctata } \\
\text { A.punctata } \\
\text { A.caviae } \\
\text { A.enteropelogenes } \\
\text { A.enteropelogenes } \\
\text { A.enteropelogenes } \\
\text { A. hydrophila } \\
\text { A.enteropelogenes } \\
\text { A. caviae } \\
\text { A. hydrophila } \\
\text { A. aquarorium } \\
\text { A. hydrophila } \\
\text { A. hydrophila } \\
\text { A. hydrophila }\end{array}$ & $\begin{array}{l}\text { S } \\
\text { S } \\
\text { S } \\
\text { S } \\
\text { S } \\
\text { S } \\
\text { S } \\
\text { S } \\
\text { S } \\
\text { S } \\
\text { S } \\
\text { S } \\
\text { S } \\
\text { S } \\
\text { S }\end{array}$ & $\begin{array}{l}\text { S } \\
\text { S } \\
\text { S } \\
\text { S } \\
\text { S } \\
\text { S } \\
\text { S } \\
\text { S } \\
\text { S } \\
\text { S } \\
\text { S } \\
\text { S } \\
\text { S } \\
\text { S } \\
\text { S }\end{array}$ & $\begin{array}{l}S \\
S \\
S \\
R \\
S \\
S \\
S \\
S \\
S \\
R \\
R \\
R \\
R \\
R \\
R\end{array}$ & $\begin{array}{l}\text { S } \\
R \\
R \\
\text { S } \\
\text { S } \\
\text { S } \\
\text { S } \\
\text { S } \\
\text { S } \\
\text { R } \\
\text { S } \\
\text { S } \\
\text { S } \\
\text { S } \\
\text { S }\end{array}$ & $\begin{array}{l}S \\
R \\
R \\
R \\
R \\
R \\
R \\
R \\
R \\
R \\
R \\
R \\
R \\
R \\
S\end{array}$ & $\begin{array}{l}\text { S } \\
\text { S } \\
\text { S } \\
\text { S } \\
\text { S } \\
\text { S } \\
\text { S } \\
\text { S } \\
\text { S } \\
\text { S } \\
\text { S } \\
R \\
\text { S } \\
\text { S } \\
\text { S }\end{array}$ & $\begin{array}{l}\text { S } \\
\text { S } \\
\text { S } \\
\text { S } \\
\text { S } \\
\text { S } \\
\text { S } \\
\text { S } \\
\text { S } \\
\text { S } \\
\text { S } \\
\text { S } \\
\text { S } \\
\text { S } \\
\text { S }\end{array}$ & $\begin{array}{l}\text { S } \\
\text { S } \\
\text { S } \\
\text { S } \\
\text { S } \\
\text { S } \\
\text { S } \\
\text { S } \\
\text { S } \\
\text { S } \\
\text { S } \\
\text { S } \\
\text { S } \\
\text { S } \\
\text { S }\end{array}$ & $\begin{array}{l}S \\
S \\
S \\
S \\
S \\
S \\
S \\
S \\
S \\
S \\
S \\
S \\
S \\
S \\
S\end{array}$ & $\begin{array}{l}\mathrm{S} \\
\mathrm{S} \\
\mathrm{S} \\
\mathrm{S} \\
\mathrm{S} \\
\mathrm{S} \\
\mathrm{S} \\
\mathrm{S} \\
\mathrm{S} \\
\mathrm{R} \\
\mathrm{S} \\
\mathrm{S} \\
\mathrm{S} \\
\mathrm{S} \\
\mathrm{S}\end{array}$ & $\begin{array}{l}S \\
S \\
S \\
S \\
S \\
S \\
S \\
S \\
S \\
S \\
S \\
S \\
S \\
R \\
S\end{array}$ & $\begin{array}{l}S \\
S \\
S \\
S \\
S \\
S \\
S \\
S \\
S \\
S \\
S \\
S \\
S \\
S \\
S\end{array}$ \\
\hline
\end{tabular}

G-Gentamycin, S-Streptomycin, A-Ampicillin, N-Nalidixic Acid, V-Vancomycin, Co-Co-Trimoxazole, T-Trimethoprim, Cef-Cefixime, AziAzithromycin, R-Rifampicin, Tetra-Tetracycline, Chlora-Chloramphenicol, S = Sensitive; $\mathrm{R}=$ Resistant

strains were able to utilise salicin for their growth. All the isolates were haemolytic on blood agar indicating their pathogenic nature. A. enteropelogenes, $A$. hydrophila and $A$. aquarorium exhibited $\beta$-hemolysis in the form of a clearance zone in the blood agar plate whereas A. caviae and A. punctata developed green colouration showing $\alpha$ haemolytic activity. All the isolates were able to grow on TCBS agar plates producing yellow or green coloured colonies.

Antibiotic susceptibility tests: The antibiogram of the Aeromonas isolates revealed the diverse pattern of resistance to vancomycin (86.66\%), ampicillin $(46.66 \%)$, nalidixic acid $(20 \%)$, tetracycline $(6.66 \%)$, co-trimaxozole $(6.66 \%)$ and rifampicin $(6.66 \%)$. All the isolates were susceptible to gentamycin, streptomycin, trimethoprim, azithromycin, cefixime and chloramphenicol. The percentage of isolates exhibiting resistance against the tested antibiotics is presented in Fig 3.

The A. hydrophila strains from prawn, aquafarms and mangroves exhibited variations in their antibiotic profile with BTPR6 from prawn being resistant to vancomycin and BTVE3 from mangroves being resistant to ampicillin and vancomycin. Among the three isolates from aquafarms, BTMA11 and BTAS5 were resistant to ampicillin and BTPF7 exhibited multiple antibiotic resistance to ampicillin, vanco- mycin and tetracycline. The A. enteropelogenes strains (BTPR1, BTPR3, BTPR4 and BTPR7) from prawn were sensitive to all the classes of antibiotics tested except vancomycin. A.punctata strains BTSQ9 and BTSQ10 from squid, were resistant to nalidixic acid and vancomycin, while BTSQ7 was sensitive to all tested antibiotics. Among the A.caviae strains, BTSQ13 from squid was resistant to ampicillin and vancomycin whereas BTMU3, the only isolate, from mussel exhibited multiple drug resistance to ampicillin, nalidixic acid, vancomycin and rifampicin. A. aquarorium (BTMA8) from aquafarm was resistant to ampicillin, vancomycin and co-trimaxozole.

The antibiogram of the 15 isolates of Aeromonas is represented in Table-2. Based on the results of antibiotic profiling, the multiple antibiotic resistance (MAR) index was calculated. $20 \%$ of the Aeromonas sp. showed MAR Index $\geq 0.2$ (data not shown) and this higher MAR index is indicative of the high risk environment.

\section{Discussion}

Aeromonas is a genus of growing interest due to its pathogenicity to aquatic organisms, its potential pathogenic effects in humans [2,6] in fishes [28] and its spoilage action in food [29].

Reports are available on the occurrence of 
Aeromonas species in squid [30], prawn [31] and mussel [32] and their potential as health hazards when associated with aquaculture settings and seafood $[12,33]$ have been well documented. In South India, the prevalence of Aeromonas in drinking water [34], finfish and prawn [35] and ornamental fishes [36,37] emphasise the need for the surveillance of this pathogen in the environmental reservoirs.

The present study analysed three tropical seafoods (squid, prawn and mussel), aquaculture and mangrove environments to reveal varying degrees of Aeromonas contamination and incidence.

Molecular identification by $16 \mathrm{~S}$ rDNA sequence analysis is a valuable tool in identification of Aeromonas species [38] and has been adopted in this study. The isolates were assigned to five species, namely, A. hydrophila (33.3\%), A. enteropelogenes (26.6\%), A. punctata (20\%), A. caviae (13.3\%) and A. aquarorium (6.6\%). The dominance of $A$. hydrophila in seafood samples over other species is in accordance with earlier studies [39,40], where it was the predominant species in the fish samples analysed. Though considered a common inhabitant of healthy fish [41] and aquatic system [42], A. hydrophila is also an established opportunistic pathogen infecting fish and man under physiological and environmental stress [40]. A. enteropelogenes was isolated from prawn in this study and has been reported earlier from prawn cultured in concrete tanks in Saudi Arabia [43]; also an opportunistic pathogen with the same pathogenicity factors and enterotoxin production as featured by $A$. hydrophila [4]. Squid isolates were A. punctata, a species associated with human gastroenteritis and fish septicaemia [44].

A. caviae, associated with gastroenteritis in humans [11] and ulcers in fish [45], predominant in faecal polluted water [46], fresh water fishes [40] and ornamental fishes [47], was obtained from squid and mussel in this study. A. aquarorium, of epidemiological significance as reported in clinical specimens from Malaysia [48], was isolated from aquafarm sediment in this study. A. aquarorium was reported to be pathogenic to man and fishes causing bacteremia and wound infections [10]. The production of hemolytic toxins has been regarded as strong evidence of pathogenic potential in aeromonads and the property of hemolysis on blood agar is directly related to enteropathogenicity [2]. $\beta$ hemolysin has been characterised in A. hydrophila, A. caviae and A. sobria [31] and $\alpha$ hemolysin in A. hydrophila [11] indicating their pathogencity. The high frequency of hemolytic activity among Aeromonas strains isolated from the various samples is indicative of the pathogenic potential of these strains and further characterisation of virulence factors are to be done to establish their degree of pathogenicity.

The phylogenetic and evolutionary relationship among the 15 species of Aeromonas elucidated using the partial 16S rDNA sequences and species level identification was possible without ambiguity.
However, microheterogeneity of the 16S rRNA gene can interfere with the proper identification of species [38] and additional molecular methods can be employed for unambiguous identification and description of new species [49]. The intraspecies diversity based on partial $16 \mathrm{~S}$ rDNA sequence analysis was observed in the variations in the biochemical reactions and antibiotic susceptibility of these strains.

Aeromonas species demonstrate marked differences in their susceptibilities to antibiotics and are generally considered resistant to ampicillin [50], tetracycline and vancomycin [51]; sensitive to cephalosporins [52] and nalidixic acid [2]. $A$. enteropelogenes has sensitivity to $\beta$ lactams [13] and our results substantiate this. A. punctata strains in this study were also ampicillin sensitive, exhibiting $100 \%$ sensitivity to gentamycin, streptomycin, co-trimoxazole, trimethoprim, cefixime, azithromycin and chloramphenicol, the results being nearly in accordance with prior studies [51,53]. Resistance to rifampicin and tetracycline exhibited by two strains should receive ample attention because these are antibiotics commonly used in aqua culture settings in developing countries and has a higher risk potential due to lateral gene transfer [50]. Analysis of the antibiotic profile of a species is significant as it aids in the design of culture media for selective isolation of species.

According to Matyar et. al., [54], MAR index values $>0.2$ indicates existence of isolates in high risk contaminated source with higher frequency of the use of antibiotics while values $<0.2$ is indicative of the lesser application of antibiotics. The higher MAR index exhibited by $20 \%$ of the isolates indicates the need for the judicious use of antibiotics as therapeutics and as prophylactic agents.

There has been a substantial increase in seafood consumption in the developed world on account of the better taste, nutritional quality and medicinal properties associated with seafood and its products. Kerala, being one of the premier fish producing states in India, holds a major position in Indian seafood exports. As the major quality criteria for seafood export is the biological status of the resource material, presence of pathogens and concentration of aquaculture drugs like antibiotic residues, hormone and pesticide residues, can pose health risks to consumers of fish and fishery products. Food safety regulations have been imposed in the industrialized markets and nonadherence to these as well as the stringency of food safety regulations cause huge losses. Furthermore, outbreaks of bacterial infections in aqua farms also lead to substantial economic loss to farmers.

The prevalence of Aeromonas species in the aquatic environment has been recognized as a potential health risk and understanding the natural reservoirs of Aeromonas will help in developing methods to monitor and control these bacteria in seafood, aquaculture settings and associated mangroves. 


\section{Conclusion}

The study revealed that seafood, aquafarms and associated mangroves of Cochin, Kerala, harbour potential pathogenic Aeromonas species and serve as environmental reservoirs to support the survival, persistence and dissemination of these pathogens. Since Kerala holds a significant position in the fisheries sector, aquaculture industries offer immense scope not only on augmenting the aquatic production but also contributing to the export earnings. There is also a growing demand for ornamental fishes both in the domestic and international markets. Due to the pathogenic nature of Aeromonas spp., monitoring the levels and species distribution of Aeromonas in seafoods and aqua culture environments is requisite to prevent risk to human and aquatic animal health. Ensuring appropriate quality control practices and coordination of the surveillance of antibiotic use and multidrug resistance in aquaculture industries are crucial to reducing overall disease incidence and resistance by these pathogens.

\section{Authors' contribution}

All authors contributed equally. All authors read and approved the final manuscript.

\section{Acknowledgements}

The first author gratefully acknowledges the support from the University Grants Commission, India for sanction of teacher fellowship under the Faculty Development programme.

\section{Competing interests}

Authors declare that they have no competing interests.

\section{References}

1. Khan, M. A., Khan, S., and Miyan, K. (2011) Aquaculture as Food Production System: AReview. Biol Med 3: 291-302.

2. Janda, J. M., and Abbott, S. L. (2010) The genus Aeromonas: Taxonomy, Pathogenicity and Infection. Clin Microbiol Rev.23: 35-73.

3. Sinha, S., Shimada, T., Ramamurthy, T., Bhattacharya, S. K., Yamasaki, S., Takeda, Y., and Balakrish Nair, G. (2004) Prevalence, Serotype Distribution, Antibiotic Susceptibility and Genetic Profiles of Mesophilic Aeromonas species Isolated from Hospitalized Diarrhoeal Cases in Kolkata, India. J. Med. Microbiol. 53: 527-534.

4. Albert, M. J., Ansaruzzaman, M., Talukder, K. A., Chopra, A. K., Kuhn, I., Rahman, M., Faruque, A. S., Islam, M. S., Sack, R. B., and Mollby, R. (2000) Prevalence of Enterotoxin Genes in Aeromonas spp. Isolated from Children with Diarrhoea, Healthy Controls, and the Environment. J. Clin. Microbiol. 38: 3785-3790.

5. Joseph, S. W., and Carnahan, A. M. (2000) Update on the Genus Aeromonas. ASM News 66: 218-223.

6. Dwivedi, M., Mishra, A., Prasad, A., Azim, A., Singh, R. K., Baronia, A. K., Prasad, K. N., and Dwivedi, U. N. (2008) Aeromonas caviae Septicemia in Immunocompetent Gastrointestinal Carriers. Braz. J. Infect. Dis. 12: 547-548.

7. Kelly, K. A., Koehler, J. M., and Ashdown, L. R. (1993) Spectrum of Extraintestinal Disease due to Aeromonas Species in Tropical Queensland, Australia. Clin. Infect. Dis. 16:574-579.

8. Reith, M.E., Singh, R. K., Curtis, B., Boyd, J. M., Bouevitch, A., Kimball, J., Munholland, J., Murphy, C., Sarty, D.,
Williams, J., Nash, J. H. E., Johnson, S. C., and Brown, L. L. (2008) The Genome of Aeromonas salmonicida subsp. salmonicida A449: Insights in to the Evolution of a Fish Pathogen. BMC Genomics 9: 427.

9. Singh, D. V., and Sanyal, S. C. (1999) Virulence Patterns of Aeromonas eucrenophila Isolated from Water and Infected Fish. J. Diarrhoeal Dis. Res 17: 37-42.

10. Figueras, M. J., Alperi, A., Saavedra, M. J., Ko, W., Gonzalo, N., Navarro, M., and Martínez-Murcia, A. J. (2009) Clinical Relevance of the Recently Described Species Aeromonas aquariorum. J. Clin. Microbiol. 47: 3742-3746.

11. Von Gravenitz, A. (2007) The Role of Aeromonas in Diarrhea: a Review. Infection 35: 59-64.

12. Ghenghesh, K. S., Ahmed, S. F., El-Khalek, R. A., Al-Gendy, A., and Klena, J. (2008) Aeromonas-Associated Infections in Developing Countries. J. Infect. Dev. Countr. 2:81-98.

13. Luca, F. D., Giraud-Morin, C., Rossolini, G. M., Docquier, J.-D., and Fosse, T. (2010) Genetic and Biochemical Characterization of TRU-1, the Endogenous Class C $\beta$ Lactamase from Aeromonas enteropelogenes. Antimicrob. Agents Ch. 54: 1547-1554.

14. Rahman, M., Huys, G., Rahman, M., Albert, M. J., Kühn, I., and Möllby, R. (2007) Persistence, Transmission, And Virulence Characteristics of Aeromonas strains in a Duckweed Aquaculture-Based Hospital Sewage Water Recycling Plant in Bangladesh. Appl. Envir. Microbiol. 73: 1444-1451.

15. Murray, M. G., and Thompson, W. F. (1980) Rapid Isolation of High Molecular Weight Plant DNA. Nucl. Acids Res. 19:4321-4326.

16. Shivaji, S., Vijaya Bhanu, N., and Aggarwal, R. K. (2000) Identification of Yersinia pestis as the Causative Organism of Plague in India as Determined by $16 \mathrm{~S}$ rDNA Sequencing and RAPD Based Genomic Fingerprinting. FEMS Microbiol. Lett. 189: 247-252.

17. Reddy, G. S. N., Aggarwal, R. K., Matsumoto, G. T., and Shivaji, S. (2000) Arthrobacter flavus sp. nov., a Psychrophilic Bacterium Isolated From a Pond in McMurdo Dry Valley. Antarctica. Int. J. Syst. Evol. Microbiol. 50:15531561.

18. Reddy, G. S. N., Prakash, J. S. S., Vairamani, M., Prabhakar, S., Matsumoto, G. 1., and Shivaji, S. (2002a) Planococcus antarcticus and Planococcus psychrophilus sp. nov., Isolated From Cyanobacterial Mat Samples Collected from Ponds in Antarctica. Extremophiles 6:253-261.

19. Reddy, G. S. N., Prakash, 1. S., Matsumoto, G., Stackebrandt, L., and Shivaji, S. (2002b) Arthrobacter roseus sp. nov., a Psychrotolerant Bacterium Isolated from an Antarctic Cyanobacterial Mat Sample. Int. J. Syst. Evol. Microbiol. 52: 1017-1021.

20. Altschul, S. F., Gish, W., Miller, W., Myers, E. W., and Lipman, D. J. (1980) Basic Local Alignment Search Tool. J. Mol. Biol. 215: 403-410.

21. Saitou N, and Nei, M. (1987) The Neighbor-Joining Method: A New Method for Reconstructing Phylogenetic Trees. Mol. Biol. Evol. 4: 406-425.

22. Tajima, F., and Nei, M. (1984) Estimation of Evolutionary Distance Between Nucleotide Sequences. Mol. Biol. Evol. $1: 269-285$.

23. Tamura, K., Peterson, D., Peterson, N., Stecher, G., Nei, M., and Kumar, S. (2011) MEGA5: Molecular Evolutionary Genetics Analysis Using Maximum Likelihood, Evolutionary Distance, and Maximum Parsimony Methods. Mol. Biol. Evol. 28:2731-2739.

24. Abbott, S. L., Cheung, W. K. W., and Janda, J. M. (2003) The Genus Aeromonas: Biochemical Characteristics, Atypical Reactions, and Phenotypic Identification Schemes. J. Clin. Microbiol. 41:2348-2357.

25. Russell, F.M., Biribo, S.S.N., Selvaraj, G., Oppedisano, F., Warren, S., Seduadua, A., Mulholland, E.K. and Carapetis, J.R. (2006) As a Bacterial Culture Medium, Citrated Sheep Blood Agar Is a Practical Alternative to Citrated Human Blood Agar in Laboratories of Developing Countries. J. Clin. 
Microbiol. 44(9) 3346-3351.

26. Bauer, A. W., Kirby, W. M., Sherris, J. C., and Turck, M. (1966): Antibiotic Susceptibility Testing by a Standardized Single Disk Method. Am. J. Clin. Path. 45: 493-496.

27. Krumperman, P. H. (1985) Multiple Antibiotic Indexing of E. coli to Identify High-Risk Sources of Fecal Contamination of Foods. Appl. Envir. Microbiol. 46: 165-170.

28. Thampuran, N., Surendran, P. K., Mukundan, M. K., and Gopakumar, K. (1995) Bacteriological Studies on Fish Affected by Epizootic Ulcerative Syndrome (EVS) in Kerala, India. Asian Fish. Sci. 8: 103-111.

29. Bezirtzoglou, E., Maipa, V., Voidarou, C., Tsiotsias, A., and Papapetropoulou, M. (2000) Food Borne Intestinal Bacterial Pathogens. Microb. Ecol. Health Dis. 2: 96-104.

30. Baldrias, L. R., and Alvero, M. A. C. (1999) Aeromonas Species from Raw Squid Balls: A Preliminary Study of a Potential Food-Borne Pathogen and Health Hazard $J$. Environ. Sci. Manag. 2: 48-52.

31. Thayumanavan, T., Vivekhanandhan, G., Savithakumari, K., Subashkumar, R., and Lakshmanaperumalsamy, P. (2003) Incidence of Haemolysin Positive and Drug Resistant Aeromonas hydrophila in Freshly Caught Finfish and Prawn Collected from Major Commercial Fishes of Coastal South India. FEMS Imm. Med. Microbiol. 36:41-45.

32. Ottaviani, D., Santarelli, S., Bacchiocchi, S., Masini, L., Ghittino, C., and Bacchiocchi, I. (2006) Occurrence and Characterization of Aeromonas spp. in Mussels from the Adriatic Sea. Food Microbiol. 23: 418-422.

33. Austin, B., and Austin, D. A. (1993) Bacterial Fish Pathogens. Ellis Horwood, Chichester, United Kingdom.

34. Mascher, F., Reinthaler, F., Schuhmann, G., Enayat, U., Sixl, W., and Klambauer, B. (1989) Microbiological and Chemical Analysis of Drinking Water in Southern India (with special consideration of Aeromonas species). Geogr Med. Suppl. 3: 135-140.

35. Vivekanandhan, G., Hatha, A. A. M., and Lakshmanaperumalsamy, C. P. (2005) Prevalence of Aeromonas hydrophila in Fish and Prawns from the Seafood Market of Coimbatore, South India. Food Microbiol. 22: 133-137.

36. Sreedharan, K., Philip, R., and Singh, I. S. B. (2012) Virulence Potential and Antibiotic Susceptibility Pattern of Motile Aeromonads Associated with Freshwater Ornamental Fish Culture Systems: A Possible Threat To Public Health. Braz. J. Microbiol. 43: 754-765.

37. Mohan, L., and Unni , A. C. B. (2012) Pathogenicity of Aeromonas hydrophila in Goldfish (Carassius auratus auratus) and Development of Vaccine for Control of Infections. Adv. Bio Tech 12: 29-31.

38. Janda, J. M., and Abbott, S. L. (2007) 16S rRNA Gene Sequencing for Bacterial Identification in the Diagnostic Laboratory: Pluses, Perils, and Pitfalls. J. Clin. Microbiol. 45: 2761-2764.

39. Hatha, A. A. M., Vivekanandhan, A. A., Joice, G. J., and Christol (2005) Antibiotic Resistance Pattern of Motile Aeromonads From Farm Raised Freshwater Fish. Int. J. Food Microbiol. 98: 131-134.
40. Yoganath, N., Bhakyaraj, R., Chanthuru, A., Anbalagan, T., and Mullai Nila, K. (2009) Detection of Virulence Gene in Aeromonas hydrophila Isolated from Fish Samples Using PCR Technique. Gl. J. Biotech. Biochem. 4: 51-53.

41. Wong, S. Y., and Leong, T. S. (1987) Current fish disease problems in Malaysia In.Fish quarantine and fish diseases in South and Southeast Asia. Asian Fisheries Society, Manila.

42. Kaper, J. B., Lockman, H., Colwell, R. R., and Joseph, S. W. (1981) Aeromonas hydrophila: Ecology and Toxigenicity of Isolates from an Estuary. J. Appl. Bacteriol. 50:359-377.

43. Al-Harbi, A. H. (2003) Bacterial Flora of Freshwater Prawn, Macrobrachium rosenbergii (de Man), Cultured in Concrete Tanks in Saudi Arabia. J. Appl. Aquaculture 14: 113-124.

44. Gilardi, G. L. (1967) Morphological and Biochemical Characteristics of Aeromonas punctata (hydrophila, liquefaciens) Isolated From Human Sources. Appl. Microbiol. 15:417-421.

45. Singh, D. V., and Sanyal, S. C. (1992) Haemolysin and Enterotoxin Production by Aeromonas caviae Isolated from Diarrhoeal Patients, Fish and Environment. J. Diarrhoeal Dis. Res. 10:16-20.

46. Stecchini, M. L., and Domenis, C. (1994) Incidence of Aeromonas species in Influent and Effluent of Urban Waste Water Purification Plants. Lett. Appl. Microbiol. 19: 237239.

47. John, N., and Hatha, A. A. M. (2012) Prevalence, Distribution and Drug Resistance of Motile Aeromonads in Freshwater Ornamental Fishes. Indian J. Fish. 59: 161-164.

48. Puthucheary, S. D., Puah, S. M., and Chuaz, K. H. (2012) Molecular Characterization of Clinical Isolates of Aeromonas Species from Malaysia. PLoS one. 7 e30205.

49. Alperi, A., Figueras, M. J., Inza, I., and Martínez-Murcia, A. J. (2008) Analysis of 16S rRNA Gene Mutations in a Subset of Aeromonas Strains and their Impact in Species Delineation. Int. Microbiol. 11: 185-194.

50. Igbinosa, I. H., and Okoh, A. I. (2012) Antibiotic Susceptibility Profile of Aeromonas Species Isolated From Wastewater Treatment Plant. Scientific World Journal Article ID 764563, 6 pages.

51. Awan, M. B., Ahmed, M., Abdul, B., and Karel, K. (2009) Antibiotic Susceptibility Profile of Aeromonas spp. Isolates from Food in Abu Dhabi, United Arab Emirates. New Microbiologica 32: 17-23.

52. Emekdas, G., Aslan, G., Tezcan, S., Serin, M. S., Yildiz, C., Ozturhan, H., and Durmaz, R. (2006) Detection of the Frequency, Antimicrobial Susceptibility and Genotypic Discrimination of Aeromonas Strains Isolated From Municipally Treated Tap Water Samples by Cultivation and AP-PCR in Turkey. Int. J. Food. Microbiol. 107:310-314.

53. Kaskhedikar, M., and Chhabra, D. (2010) Multiple Drug Resistance in Aeromonas hydrophila Isolates of Fish. Vet. World 3: 76-77

54. Matyar, F., Kaya, A., and Dincer, S. (2007) Distribution and Antibacterial Drug Resistance of Aeromonas spp. from Fresh and Brackish Waters in Southern Turkey. Ann. Microbiol. 57: 443-447. 